\section{QIJEI}

International Journal for

Educational Integrity

\title{
Editorial Volume 9(2)
}

Welcome to the last issue of the IJEI for 2013.

It has been an exciting year with numerous conferences and research on academic integrity around the world. Auckland University of Technology kicked off the year with the Fraud, Fakery and Fabrication: Academic and research integrity conference, the International Center for Academic Integrity held their annual conference in San Antonio on 28 February, the National Roundtable and Australian National Speaking Tour for the Exemplary Academic Integrity Project was also held in late February and early March, the $3^{\text {rd }}$ World Conference on Research Integrity was held in Montreal in May, the Plagiarism across Europe and Beyond Conference shared the results of the 'Impact of policies for plagiarism in higher education across Europe' project in Brno, Czech Republic in June, and the $6^{\text {th }}$ Asia Pacific Conference on Educational Integrity showcased the work of Australian Office for Learning and Teaching commissioned projects on academic integrity in Sydney in October.

With so much interest and research on this topic across a range of countries and contexts, it is perhaps not surprising that the current issue is an eclectic mix of reflective, conceptual, empirical and case study work from researchers spanning six countries, including the United Arab Emirates, Norway, Australia, Sweden, Indonesia and the UK. The issue covers diverse topics extending from the development of academic skills, to motivations and predictors of student plagiarism, systems to reduce plagiarism and the responsibility of universities to provide marketing information based on ethical principles of honesty and trustworthiness. Student groups represented include secondary school, undergraduate and postgraduate.

Radhika lyer-O'Sullivan, formerly of the British University in Dubai, analyses faculty feedback, samples of student writing and Turnitin Similarity Reports to determine if teaching critical reading as a threshold concept results in critical thinking and subsequently improved critical writing skills. While the sample was small and the results inconclusive, Iyer-O'Sullivan makes the case that teaching critical reading assists students to understand the importance of using supporting evidence to develop a convincing academic argument.

Håvard Skaar and Hugo Hammer from Oslo and Akershus University College, Norway use a mixed-methods approach to explore secondary school students' plagiarism of internet sources in essay writing. The survey of 67 students indicated that $75 \%$ of students reported plagiarising from online sources and that plagiarism accounted for $25 \%$ of the total amount of text. Students with a higher grade in written Norwegian plagiarised less than those with a lower grade, and students more conversant with appropriate citation practices plagiarised less than those students less familiar with referencing conventions. Qualitative feedback from interviews with 29 students indicated that the students wanted to spend as little time and effort as possible on the assessment task and that plagiarism was chosen as a writing strategy, with little reflection on the moral aspects on this decision.

In contrast, Rebecca Awdry, from the University of Canberra, and Rick Sarre, from the University of South Australia, found that the university students in their study expressed strong ethical positions in relation to plagiarism, arguing that it was cheating and dishonest. Awdry and Sarre explored students' motivations to plagiarise using a mixed methods approach, and analysed the data through the prism of

The International Journal for Educational Integrity is available online at:

http://www.ojs.unisa.edu.au/journals/index.php/IJEl/

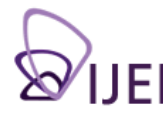


criminological theory. The authors conclude that while rational choice theory provides some insight into student breaches of academic integrity, there is an apparent disconnect between the way that academics view students' behaviour and how students themselves express their motivations. In agreement with key writers in the field (Bertram Gallant, McCabe, Bretag et al.), Awdry and Sarre conclude that higher education providers should focus less on detection and punishment and more on developing a values-based culture of integrity.

Based on a sample of 362 undergraduate psychology students, and in the context of the Indonesian government's position that any form of plagiarism "is a serious offense that may even be classified as an illegal action", Ide Bagus Siaputra, from Universitas Surabaya, explores the proposition that "regardless of the presence or absence of opportunities and the severity of the potential sanctions, some individuals seem to be prone to plagiarism". Siaputra builds on the work of Williams, Nathanson and Paulhus (2010), to propose five variables as predictors of plagiarism, including procrastination, performance, personality, perfectionism, and achievement motivation, and names the model 'the 4PA of plagiarism'. Findings from the author's study indicate that procrastination was the key predictor of plagiarism, followed by achievement motivation.

Looking to provide a multi-pronged response to student plagiarism, Ken Larsson and Henrik Hansson from Stockholm University, Sweden share the results of an innovation at their university. The digital system called SciPro was developed to support independent student thesis work, decrease the burden on supervisors for feedback on basic skills, and reduce plagiarism. The system includes a number of modules which facilitate management, communication and learning. According to the authors, SciPro works to prevents plagiarism by providing: 1) clear instructions about rules and regulations for students and supervisors; 2 ) an online peer-review system; 3 ) transparent online communication and file storage of accumulated manuscripts; and 4) a final seminar module enabling automatic generation of originality reports from Turnitin when students upload their final thesis manuscripts. Larsson and Hansson report that the implementation of SciPro has resulted in substantial improvements in policy development, successful integration of anti-plagiarism software, and an increased awareness of plagiarism issues.

The final paper in the issue reminds us that academic integrity is an issue which underpins every aspect of the educational enterprise and goes well beyond plagiarism in student assessment. Educational psychologist, John Bradley, from the UK, offers a typology of nine misleading data-based marketing claims based on his examination of UK university prospectuses. Bradley's analysis leads him to assert that marketing of higher education should aspire to higher ethical standards than marketing in general because of the high stakes involved for a potentially vulnerable group, and because the reputation of the university is founded on having high standards of scholarship. Rather than rely on external regulators to ensure the authenticity of marketing claims, the author advocates a system of voluntary peer review of university marketing prospectuses based on the principles of research and publication ethics.

I trust you will enjoy this varied issue which will interest teachers, researchers, policymakers, administrators and marketers of education, in both secondary and tertiary contexts. Volume 10(1) of the IJEI, to be published in June 2014, will include the best reviewed papers from the Plagiarism Across Europe and Beyond Conference, Czech Republic 2013, along with appropriate papers submitted via the IJEI platform.

Tracey Bretag, IJEI Editor

Email: tracey.bretag@unisa.edu.au 